\title{
1 Wind field effect on the power generation and aerodynamic performance of
}

5 Abstract

\section{offshore floating wind turbines}

\author{
Liang Li, Yuanchuan Liu, Zhiming Yuan*, Yan Gao \\ Department of Naval Architecture, Ocean and Marine Engineering, University of Strathclyde, UK
}

\begin{abstract}
This study is aimed at investigating wind field effect on the power generation and the aerodynamic performance of offshore floating wind turbines. For this purpose, three comparative wind fields are generated: a uniform wind field, a steady wind field with wind shear, and a turbulent wind field. Aerohydro-servo coupled analysis is performed in time-domain to estimate how a referenced semisubmersible offshore floating wind turbine behaves in the three wind fields. The results reveal the importance of wind shear and inflow turbulence to the performance of the floating wind turbine. Thrust force and power generation become very unstable in the presence of inflow turbulence. Due to the control strategy of the wind turbine, the power generation is also correlated with operational state and turbulence frequency. Although wind shear has a tiny effect on the rotor performance, the local aerodynamic load applied at a single blade experiences fluctuation with the presence of wind shear. It is also shown that the ultimate structural and fatigue damage loads at blade root are augmented by inflow turbulence and wind shear.
\end{abstract}

Keywords: wind field; inflow turbulence; wind shear; power generation; aerodynamic performance; offshore floating wind turbine

\section{Introduction}

Global demand for energy is expected to climb by up to $25 \%$ [1] by 2040 and the world is pursuing economic and sustainable energy sources to keep up with this considerable demand growth. In such circumstance, the utilization of offshore wind energy resources is stimulated, leading to the development of offshore floating wind turbine. Statoil [2] proposed a Spar-buoy floating wind turbine, namely the Hywind concept, which is the first full-scale floating wind turbine that has ever been built. Principle Power installed a full-scale 2MW WindFloat prototype near the coast of Portugal [3]. Most recently, Hywind Scotland, the world's first floating wind farm, already starts to deliver electricity to the grid [4]. In addition to the installation of full-scale floating wind turbines, a series of model test researches have been performed in the meanwhile [5-7]. The noticeable feature of offshore floating wind turbines compared with traditional land-based wind turbines is that the wind turbine is mounted on a floating platform displaced in the waves with mooring system. Therefore, the floating wind turbine

" Corresponding author. Department of Naval Architecture, Ocean \& Marine Engineering, University of Strathclyde.

E-mail address: zhiming.yuan@ @strath.ac.uk (Z.M. Yuan). 
is also subject to wave loads. Besides, the dynamics of mooring lines also have an influence on the response of floating wind turbines. Consequently, the study of offshore floating wind turbine is a multidisciplinary coupled analysis. Liu et al. [8] developed a CFD simulation tool for the fully coupled model of floating wind turbines. The aero-hydro-mooring coupled response of an integrated floating wind turbine was examined in $[9,10]$.

So far, the uniform wind field is usually assumed in the studies of floating wind turbine to simplify the aerodynamic modelling [8-12]. Nevertheless, the real wind field in the natural world is far more complex. Wind is by nature motion of air in the planetary boundary layer, and a stochastic process at time and space scales [13] (see Fig. 1). The near-ground wind field is essentially gust or turbulent wind, the modelling of which is usually based on classical assumptions on the probability density function of wind speed and the shape of the wind profiles under various atmospheric stability conditions. That is to say, the inflow turbulence and the wind shear are two basic features of a wind field. A couple of approaches have been proposed, including the Kaimal and the Karman models, to model the inflow turbulence. Most turbulence models are based on spectral method, which divides the turbulent inflow into a set of turbulence components with various frequencies. In the space scale, the near-ground wind field also varies with height. Popular models describing the wind profile include the power-law wind profile, the low-level jet wind profile and the logarithmic wind profile.

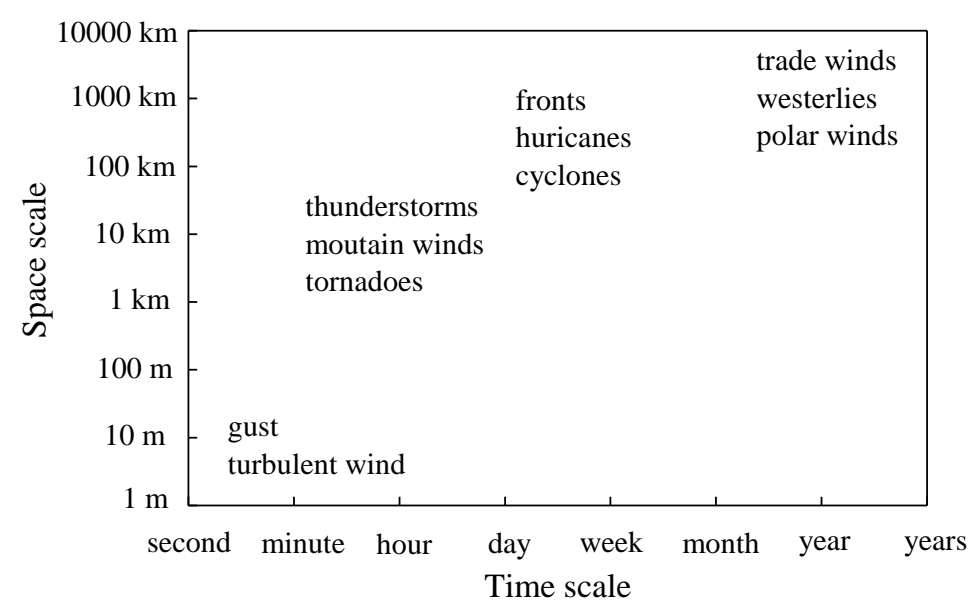

Fig. 1. Classification of wind.

Apparently, the uniform wind field is deficient to evaluate the performance of offshore floating wind turbines. In fact, previous measurements on land-based wind turbines have shown that the wind field has an observable influence on the aerodynamic performance. Lubitz [14] investigated the ambient turbulence on the energy production of a small wind turbine. It was concluded that turbulence was beneficial to the power production at low wind speeds whereas reduced the power production at high wind speeds. Li et al. [15] carried out model test in wind channel to study how the power generation of a horizontal axis wind turbine reacted to the turbulent inflow. According to their measurement, the optimum power coefficient was dependent on the turbulence intensity. Chamorro et al. [16] launched an experiment to study the unsteady behaviour of a full-scale $2.5 \mathrm{MW}$ wind turbine in turbulent inflow. 
Their measurement also revealed a correlation between the turbulence intensity and the power production. Similar relationship was observed by Lee et al. [17] in the field measurement of a small vertical-axis wind turbine installed on the rooftop of a building. In addition to the inflow turbulence, the realistic wind field also varies in vertical direction so that the wind shear effect should be considered as well. Shen et al. [18] used the lifting surface method to simulate the unsteady and periodic blade root loads and wind turbine performance in the presence of wind shear. Sezer-Uzol and Uzol [19] showed that the existence of wind shear can create a very complex wake structure with substantial asymmetries, streamwise vorticity generation, and non-periodicities downstream of the turbine rotor. Dolan and Lehn [20] developed an analytical formulation for the torque of a three-bladed wind turbine with consideration of the wind shear. They showed that the torque and the thrust force were only very slightly influenced by the wind shear, but the local aerodynamic loads on a single blade were sensitive to the wind shear. Similar phenomenon was observed by Li et al. [21].

Although the effects of inflow turbulence and wind shear on the aerodynamic performance of wind turbines have been manifested in previous studies, they were examined with a bottom-fixed wind turbine, and no wind turbine active control was considered. In real practice, the floating platform undertakes motions under joint aerodynamic and hydrodynamic excitations. Also, an offshore floating wind turbine always incorporates a controller to regulate its power generation subject to various wind speeds. For a floating wind turbine, the wind field effect may show new characteristics due to the aerohydro-servo couplings. This study is aimed at investigating the effect of wind field on the performance of offshore floating wind turbines, in terms of power generation, thrust force and blade root bending moment. Aero-hydro-servo coupled analysis is conducted in time-domain to capture the performance of a semisubmersible floating wind turbine in three categories of wind fields, namely a uniform wind field, a steady wind field with consideration of wind shear and a turbulent wind field. The discussions will be highlighted on how the performance of the floating wind turbine reacts to the wind shear and the inflow turbulence.

\section{Model Description}

As shown in Fig. 2, the OC4 DeepCwind semisubmersible concept [22] is considered in this work. The wind turbine is the NREL 5 MW baseline wind turbine [23], which incorporates a variable-speed torque controller and a blade pitch controller to regulate the power generation based on the operational state. In below-rated state, the control strategy is to maximize the power generation by adjusting the rotor speed. In over-rated state, the controller regulates the power generation by increasing the blade pitch angle. The diameter of the rotor is $126 \mathrm{~m}$, and the hub height is $90 \mathrm{~m}$. 


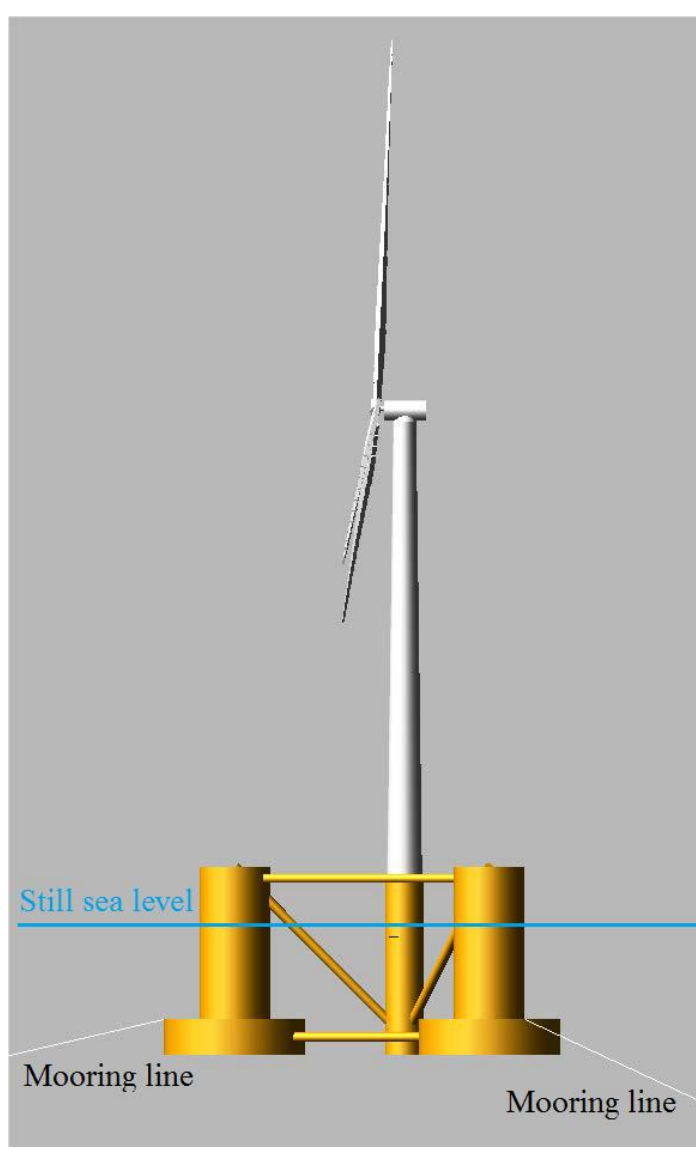

Fig. 2. DeepCwind floating wind turbine system design [24].

A three-column submersible platform is used to carry the wind turbine (see Fig. 3). The platform is made up of three main offset columns inducing buoyance and restoring force, one central column supporting the wind turbine, as well as a series of diagonal cross and horizontal bracing components. To gain a good hydrostatic stability performance, a ballast tank is installed at the bottom of each main offset column. The main scantlings of the platform are listed in Table 1.
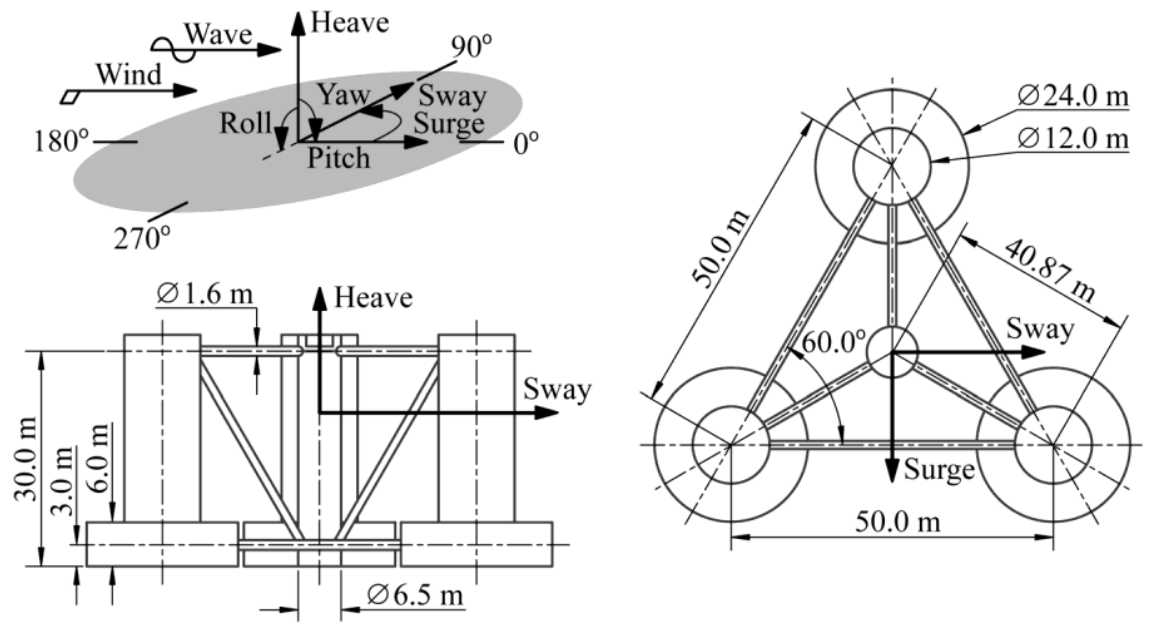

Fig. 3. Main dimensions of the submersible platform [24]. 
102 Main scantlings of the platform

\begin{tabular}{cc}
\hline Term & Value \\
\hline Draft & $20 \mathrm{~m}$ \\
Elevation of platform top & $10 \mathrm{~m}$ \\
Elevation of offset columns & $12 \mathrm{~m}$ \\
Spacing between offset columns & $50 \mathrm{~m}$ \\
Length of upper columns & $26 \mathrm{~m}$ \\
Length of base columns & $6 \mathrm{~m}$ \\
Depth to top of base columns & $14 \mathrm{~m}$ \\
Diameter of main column & $6.5 \mathrm{~m}$ \\
Diameter of offset (upper) columns & $12 \mathrm{~m}$ \\
Diameter of base columns & $24 \mathrm{~m}$ \\
Platform mass & $13,473,000 \mathrm{~kg}$ \\
Displacement & $13,986.8 \mathrm{~m} 3$ \\
Centre of mass & $(0 \mathrm{~m}, 0 \mathrm{~m},-13.5 \mathrm{~m})$ \\
Platform roll inertia & $6.827 \times 10^{9} \mathrm{~kg} \cdot \mathrm{m}^{2}$ \\
Platform pitch inertia & $6.827 \times 10^{9} \mathrm{~kg} \cdot \mathrm{m}^{2}$ \\
Platform yaw inertia & $1.226 \times 10^{10} \mathrm{~kg} \cdot \mathrm{m}^{2}$ \\
\hline
\end{tabular}

103

110

The floating wind turbine is displaced at sea site with a water depth of $200 \mathrm{~m}$. The mooring system is composed of three catenary lines. The three mooring lines are oriented symmetrically at $60^{\circ}, 180^{\circ}$, and $300^{\circ}$ about the vertical axis. Fairleads are connected to the tops of ballast tanks. The relevant properties of mooring lines are outlined in Table 2.

Table 2

Properties of mooring line.

\begin{tabular}{cc} 
Term & Value \\
\hline Depth to anchor & $200 \mathrm{~m}$ \\
Depth to fairlead & $14 \mathrm{~m}$ \\
Radius to anchor & $853.7 \mathrm{~m}$ \\
Radius to fairlead & $40.868 \mathrm{~m}$ \\
Unstretched mooring line length & $835.5 \mathrm{~m}$ \\
Mooring line diameter & $0.0766 \mathrm{~m}$ \\
Equivalent line mass density & $113.35 \mathrm{~kg} / \mathrm{m}$ \\
Equivalent mooring line extensional stiffness & $753.6 \mathrm{MN}$ \\
\hline
\end{tabular}

\section{Methodology}

The aero-hydro-servo coupled simulation code FAST [25] developed by the National Renewable Energy Laboratory (NREL) is used to simulate the dynamic performance of the DeepCwind floating wind turbine in various wind fields.

\subsection{Hydrodynamic modelling}

The wave kinetics are addressed within the framework of potential flow theory, assuming that the fluid is inviscous, incompressible and irrotational. Three components of hydrodynamic loads are accounted: hydrostatic force, radiation wave force (including memory effect of the free water surface), and wave excitation force. Since the natural period of horizontal motion of the floating wind turbine is 
sufficiently long, second-order drift wave forces are also considered to capture the low-frequency responses of the floating wind turbine. The hydrodynamic coefficients (added mass, potential damping, wave force transfer function) are firstly calculated in frequency domain. By applying the Inverse FFT (fast Fourier transform), the frequency-dependent coefficients are transformed to time-domain to complete the simulations.

\subsection{Aerodynamic modelling}

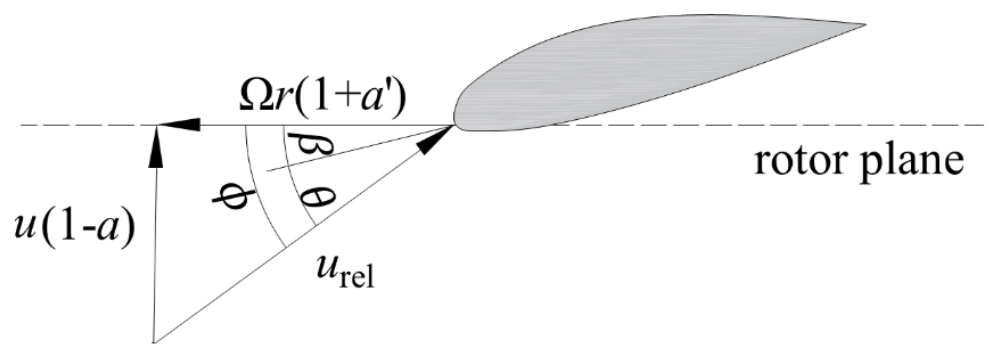

Fig. 4. Local inflow velocity at blade element.

Aerodynamic calculations are based on the blade element momentum (BEM) method, where the blade is divided into a set of elements, and the elements are assumed independent from each other. The distributed pressure and shear stress at each element are approximated by lift force and drag force. As shown in Fig. 4, the BEM method calculates aerodynamic loads by evaluating the relative inflow speed seen the by the blade element

$$
\begin{aligned}
& u_{r e l}=u \sqrt{(1-a)^{2}+\left[\frac{r \Omega}{u}\left(1+a^{\prime}\right)\right]^{2}} \\
& \theta=\phi-\beta \\
& \tan \phi=\frac{u}{r \Omega} \cdot \frac{1-a}{1+a^{\prime}}
\end{aligned}
$$

where $r$ is the radius of the blade element and $\Omega$ is the rotor speed. $\beta$ is the blade pitch angle. $a$ and $a$, are the so-called axial and rotational induction factors, which are functions of attack angle $\theta$ and aerodynamic coefficients of the blade. In practice, an initial condition of $a$ and $a$ ' is set, and the relative speed is obtained. Afterwards, update $a$ and $a$ ' with the obtained relative speed. Iterate the process until $a$ and $a$ ' converge, and the local aerodynamic loads are estimated by

$$
\begin{aligned}
& d T=\frac{1}{2} \rho \frac{u^{2}(1-a)^{2}}{\sin ^{2} \phi} c\left(C_{l} \cos \phi+C_{d} \sin \phi\right) d r \\
& d M=\frac{1}{2} \rho \frac{u(1-a) \Omega r\left(1+a^{\prime}\right)}{\sin \phi \cos \phi} c\left(C_{l} \sin \phi-C_{d} \cos \phi\right) r d r
\end{aligned}
$$

where $\rho$ is the air density; $c$ is the chord length; $C_{l}$ and $C_{d}$ are the lift coefficient and drag coefficient, respectively. 
The iteration indicates that the relative velocity determined by the BEM method reacts

143 instantaneously to the change of incident inflow. In fact, the BEM method is a quasi-steady approach

144 and thereby it is usually applied in the steady problem, where the incident inflow is constant. For an

145 offshore floating wind turbine, both the platform motions and the wind turbulence produce unsteadiness

146 of the inflow seen by the rotor. The hysteresis effect caused by the unsteady inflow is accounted by the

147 extended Beddoes-Leishman (B-L) model developed by Minnema [26], which can be regarded as a

148 correction to the induced velocity determined by the BEM method.

\subsection{Wind turbine control}

A variable-speed torque controller and a blade pitch controller are incorporated to the wind turbine.

The two control systems are designed to work independently, for the most part, in the below-rated and above-rated wind-speed range, respectively. The goal of the variable-speed torque controller is to maximize the power capture below the rated operation point. The goal of the blade-pitch controller is to regulate the generator power above the rated operation point. Fig. 5 illustrates the steady aerodynamic performance of the NREL $5 \mathrm{MW}$ baseline wind turbine under the regulation of the two controllers.

156 When the wind speed is lower than the rated value $(11.4 \mathrm{~m} / \mathrm{s})$, the variable-speed torque controller is 157 active to tune rotor speed while the blade pitch is fixed at 0 deg to extract as much wind power as 158 possible. Within this range, the aerodynamic performance is quite sensitive to the wind speed, and the power, the thrust force as well as the torque increase considerably with the wind speed. In over-rated state, the blade pitch controller is active, and the rotor speed is fixed at $12.1 \mathrm{rpm}$. The blade is pitched to feather to regulate the power generation. Meanwhile, the thrust force reduces as a result of the increase of blade pitch angle. 

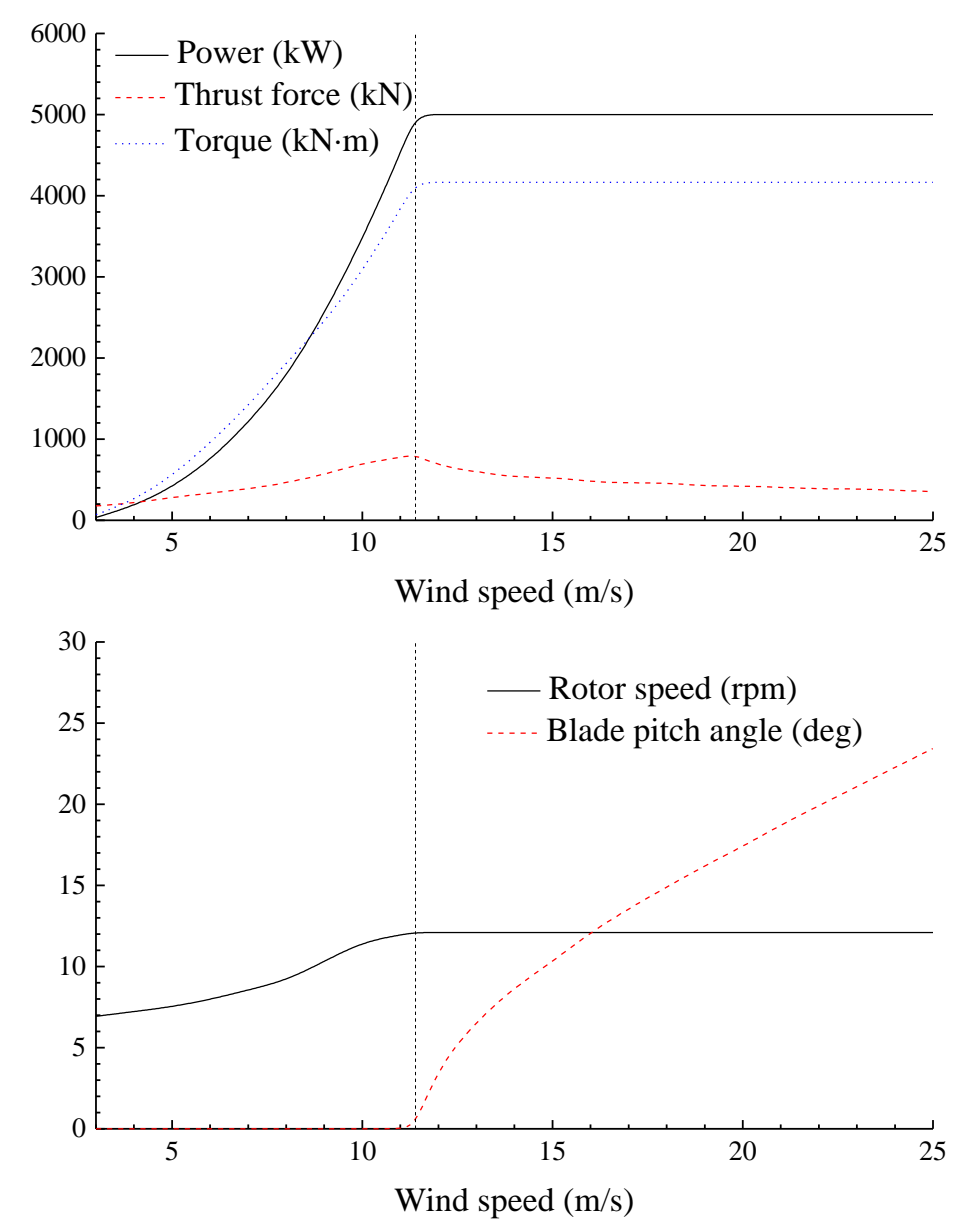

Fig. 5. Steady aerodynamic performance of the wind turbine.

\section{4. $\quad$ Mooring system modelling}

166 The lumped-mass model is used for the dynamics of mooring lines connected to the floating platform.

167 As shown in Fig. 6, the mooring line is divided into a set of evenly-sized segments, which are 168 represented by connected nodes and spring-damper systems. Each segment is divided into two 169 components and the properties are assigned and lumped to the two nodes at each end of that segment, 170 respectively. The connections between adjacent nodes are represented by damper-spring systems. Only 171 the axial properties of the mooring lines are accounted whereas the torsional and bending properties are neglected.

\section{Segment 2}

\section{Segment 1}

\section{Node 1}

\section{Node 2}

Fig. 6. Lumped-mass model of mooring line. 


\section{Environmental conditions}

176 In the natural world, the sea waves and offshore wind are always correlated. The joint wind-wave model for the Statfjord site in the northern North Sea is used in this work [27]. Firstly, the mean wind speed $u$ at hub height (90 $\mathrm{m}$ above the mean sea level) is chosen. Subsequently, the fitting curve provided in [27] is used to acquire the mean significant wave height $H_{s}$ corresponding to a given mean wind speed. Finally, the mean peak period $T_{p}$ at given $u$ and $H_{s}$ is determined by Eq. (3). The environmental conditions considered are listed in Table 3. The wind and waves propagate along positive surge direction in all simulation cases.

$$
T_{p}=\left(4.883+2.68 \cdot H_{s}^{0.529}\right) \cdot\left[1-0.19 \cdot\left(\frac{u-\left(1.764+3.426 \cdot H_{s}^{0.78}\right)}{1.764+3.426 \cdot H_{s}^{0.78}}\right)\right]
$$

Table 3

185 Joint wind and waves conditions

\begin{tabular}{llll}
\hline & $u(\mathrm{~m} / \mathrm{s})$ & $H_{s}(\mathrm{~m})$ & $T_{p}(\mathrm{~s})$ \\
\hline LC1 & 5.09 & 2.1 & 9.74 \\
LC2 & 8.14 & 2.55 & 9.86 \\
LC3 & 10.17 & 2.88 & 9.98 \\
LC4 & 14.24 & 3.62 & 10.29 \\
LC5 & 18.31 & 4.44 & 10.66 \\
LC6 & 22.37 & 5.32 & 11.06 \\
\hline
\end{tabular}

Given that the rotor diameter is $126 \mathrm{~m}$, a wind grid with dimension $180 \mathrm{~m} \times 180 \mathrm{~m}$ is generated (see Fig. 7). Such configuration guarantees that the wind grid will cover the rotor all the time. 441 points $(21 \times 21)$ are uniformly distributed across the area, at which the time-series of wind speed are generated. As shown in Fig. 8, three comparative wind fields are generated for each load case, and the mean wind speeds at hub height of the three wind fields are identical. 
192

193

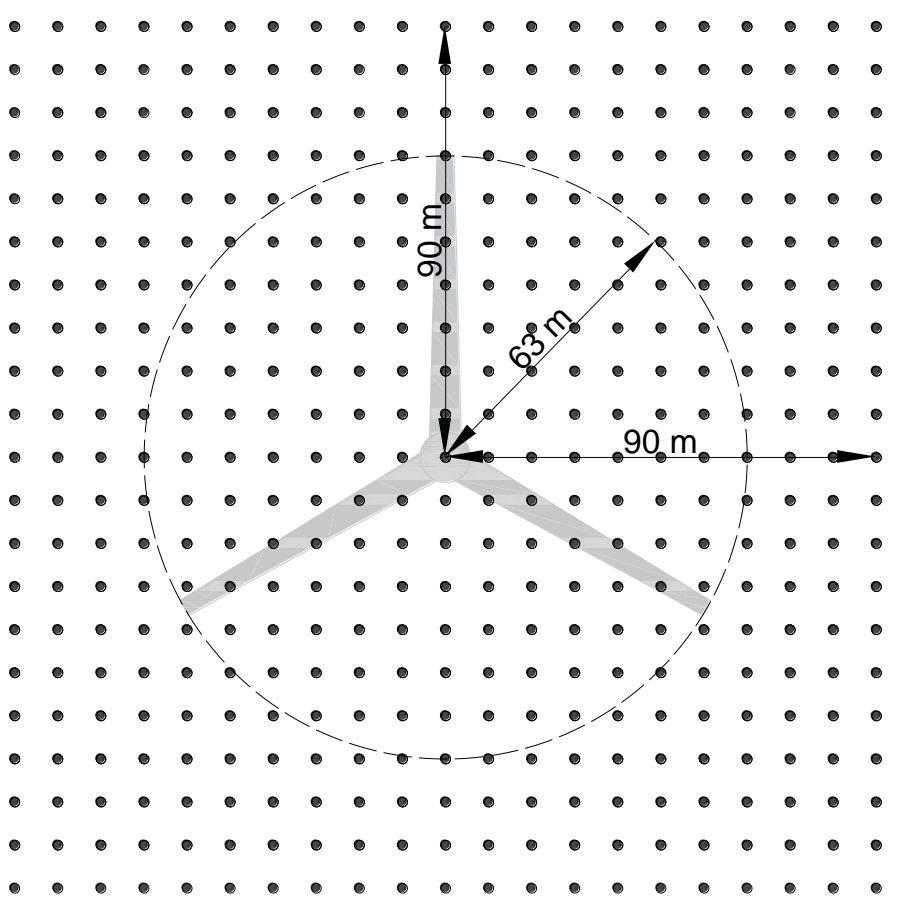

Fig. 7. Wind grid.

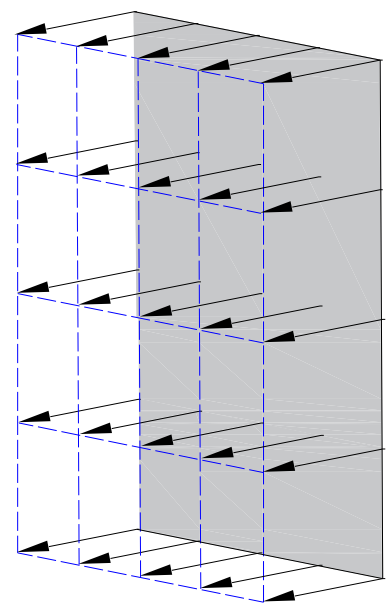

a

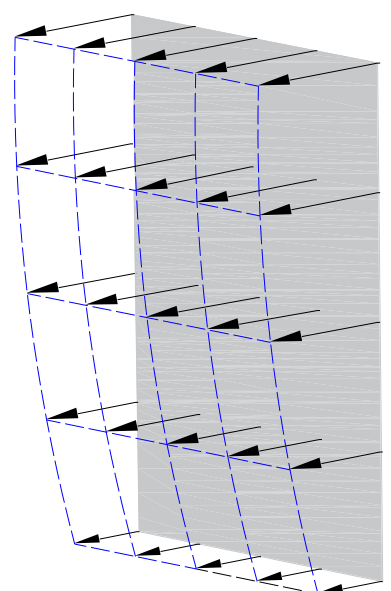

b

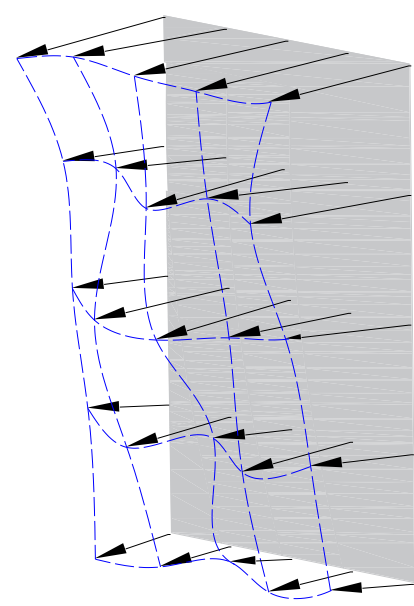

c

Fig. 8. Three wind fields. (a) uniform wind field; (b) steady wind field with wind shear; (c) turbulent wind field.

The first wind field is uniform. The wind speed vector is constant, independent on spatial position and time. It is the wind field that used in most studies of offshore floating wind turbine.

The second one is a steady wind field with consideration of wind shear, where the wind speed varies only with height. The power-law model is used to represent the wind profile,

$$
u(z)=u\left(\frac{z}{90}\right)^{\alpha}
$$

where $\alpha$ is the exponent parameter. Fig. 9 shows the wind profiles with different values of $\alpha$. The wind shear becomes more significant when $\alpha$ increases. When $\alpha$ is equal to 0 , the wind shear is omitted, and the wind field reduces to the uniform one. In our study, $\alpha=0.25$ is used. 




Fig. 9. Wind profile.

The first two wind fields are time-independent and the direction of inflow is always along $X$ axis. In the natural world, the wind speed not only varies in space scale but also depends on the time. Therefore, a turbulent wind model should be adopted to describe this feature. The IEC Kaimal turbulent model [28] is used to represent the turbulence in time scale. The time-series of wind speed are generated based on the spectral method

$$
S_{k}(f)=\frac{4 \sigma_{k}^{2} L_{k} / u}{\left(1+6 f L_{k} / u\right)^{5 / 3}}
$$

where $f$ is the cyclic frequency; $k$ indicates the direction (longitudinal 1 , lateral 2 , vertical 3 ); $L_{k}$ is defined by Eq. (6)

$$
L_{k}= \begin{cases}8.10 \Lambda & k=1 \\ 2.70 \Lambda & k=2 \\ 0.66 \Lambda & k=3\end{cases}
$$

where $\Lambda$ is the turbulence scale parameter

$$
\Lambda=0.7 \min (60, \text { hub height })
$$

$\sigma_{k}$ is the standard deviation, which is defined by the turbulence intensity $\delta$

$$
\begin{aligned}
& \sigma_{1}=\frac{\delta}{100} u \\
& \sigma_{2}=0.8 \sigma_{1} \\
& \sigma_{3}=0.5 \sigma_{1}
\end{aligned}
$$

According to above equations, the spectrum of turbulent wind is totally dependent on the turbulence intensity $\delta$ and the mean wind speed $u$. In the natural world, the turbulence intensity is correlated with the mean wind speed, and the IEC category B turbulence model is used to determine the turbulence intensity with respect to a given $u$. Fig. 10 shows the turbulence intensity and the corresponding standard 
223 deviation of longitudinal speed component at various mean wind speed. Although turbulent wind field

224 with high mean speed is has a small turbulence intensity, the standard deviation of wind speed is higher.
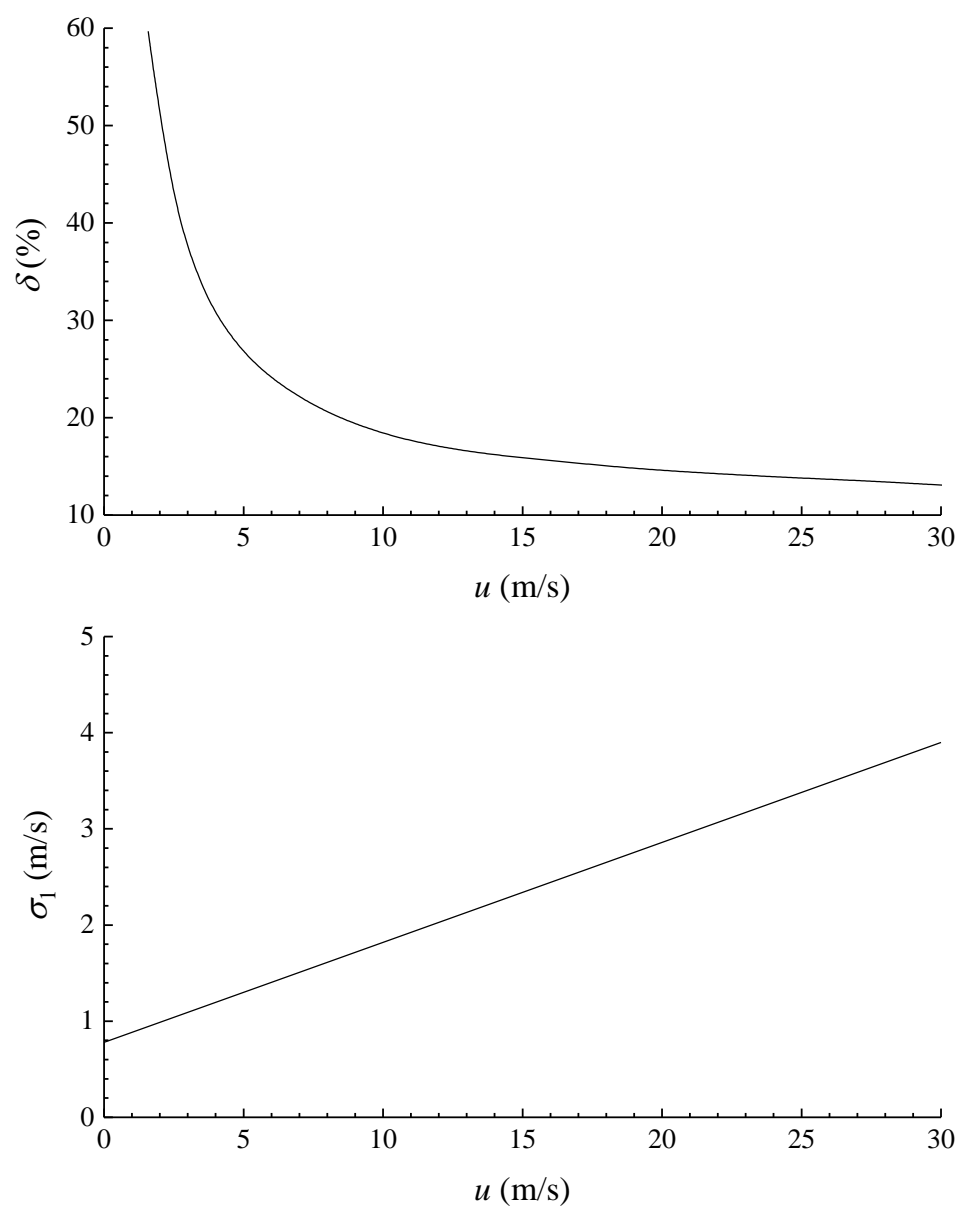

Fig. 10. Turbulence intensity and standard deviation of longitudinal wind speed as functions of mean wind speed.

Fig. 11 displays the spectrum of turbulent wind and Fig. 12 plots the corresponding time-series of wind speed. As shown, slow-varying component dominates the turbulent wind. Not only the amplitude of the wind speed varies, but also the speed direction is time-dependent.

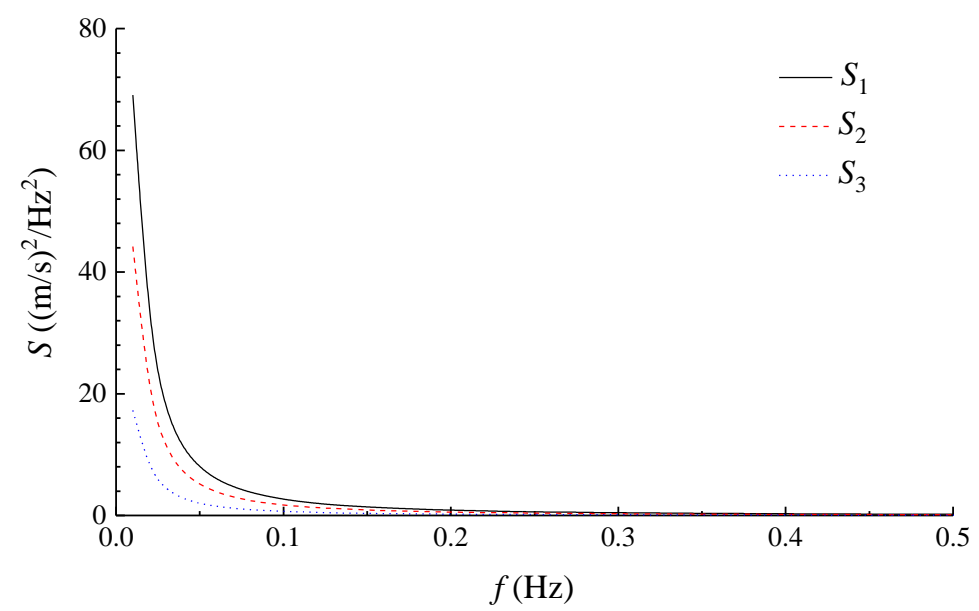

Fig. 11. Spectrum of IEC Kaimal turbulent wind, $u=10.17 \mathrm{~m} / \mathrm{s}$. 


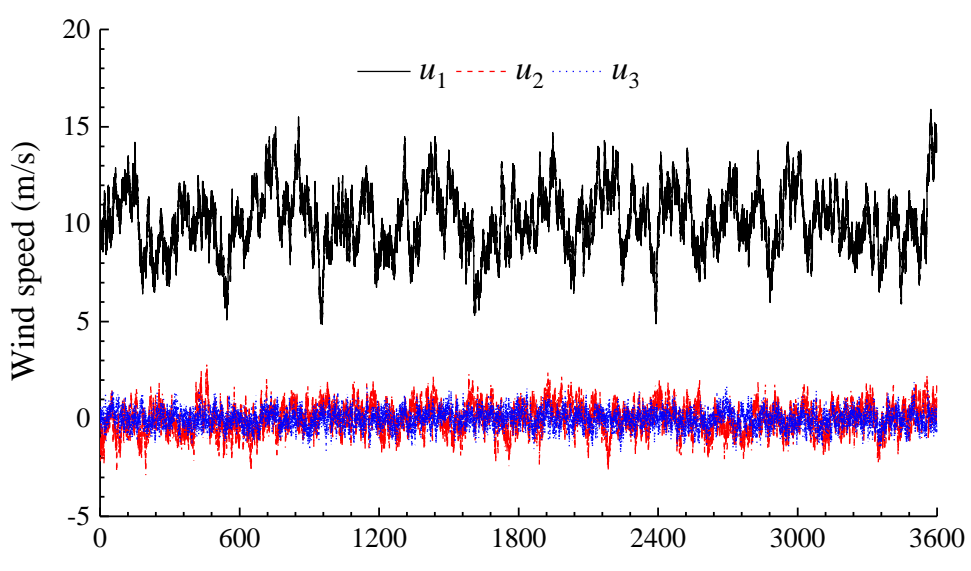

Time (s)

Fig. 12. Time-series of wind speed at height hub, $u=10.17 \mathrm{~m} / \mathrm{s}$.

Apart from the variation in time scale, the velocity of turbulent wind field is not uniformly distributed across the rotor plane in a time instant, leading to the space scale turbulence. A spatial coherence model is introduced to represent the phase difference of wind velocity at different spatial points

$$
\begin{aligned}
& \operatorname{Coh}_{i, j}(f)=\frac{\left|S_{i, j}(f)\right|}{\sqrt{S_{i}(f) S_{j}(f)}} \\
& \operatorname{Coh}_{i, j}(f)=\exp \left[-12 \sqrt{\left(\frac{f r}{u}\right)^{2}+\left(0.12 \frac{r}{L_{c}}\right)^{2}}\right] \\
& L_{c}=\min (60, \text { hub height })
\end{aligned}
$$

where $S_{i, j}$ is the cross spectrum defining the correlation of the random wind speed at points $i$ and $j, r$ is the distance between the two points.

\section{Results}

The effects of wind shear and inflow turbulence on the performance of the DeepCwind floating wind turbine will be investigated in this section, in terms of thrust force, power generation and blade root bending moment. For all load cases, the simulation runs $4000 \mathrm{~s}$ and only the last $3600 \mathrm{~s}$ data are collected to get rid of the transient effect arising in initial simulation stage. The time step is set to 0.0125 s.

\subsection{Thrust force}

Fig. 13 illustrates the effect of wind shear on the rotor thrust force. It shows that the wind shear effect is limited, which is consistent with previous studies [20,21]. When a blade is experiencing the high wind velocity region (up half of the rotor plane), the other two blades are within low wind velocity region (down half of the rotor plane). Therefore, the resultant thrust force induced by the three blades 

variation due to the wind shear, and this will be discussed in the following part of this paper.
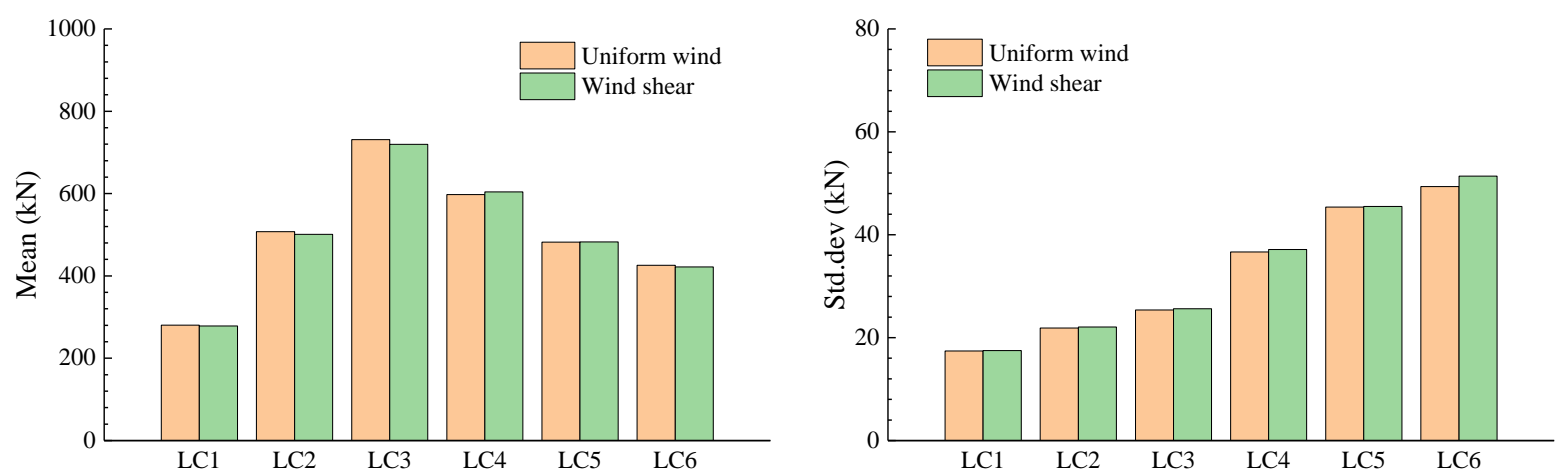

Fig. 13. Thrust force with various wind shear.

The statistics of thrust force in the turbulent wind field are showed in Fig. 14. Similarly, the average thrust force is just slightly varied by the turbulence. Although the inflow is turbulent, the mean wind speed is identical to that of the uniform wind field. Therefore, the mean thrust force acting on the rotor is nearly the same. Nevertheless, the standard deviation is augmented significantly due to the inflow turbulence. Fig. 15 gives an example of the thrust force time history, where it can be seen that the thrust force becomes very unstable in the presence of turbulence. Fig. 16 shows the FFT analysis result of thrust force. Observable low-frequency response component is excited in the turbulent wind field. As shown in Fig. 11, the turbulent wind is characterized by slow-varying component, and thereby the lowfrequency component is mainly induced by the very slow variation of wind speed in time scale. Additionally, the blades experience inflow velocity fluctuation during the rotation due to the space scale turbulence, and thereby the thrust force is also excited at the 3P rotor frequency. The high-frequency responses of wind turbines are relatively difficult to monitor, and various approaches have been proposed. For example, Lind et al. [29] developed a normal behaviour model to monitor high-frequency wind turbine vibrations. The excitation of high-frequency thrust force highlights the importance of wind turbulence to the design of wind turbines.
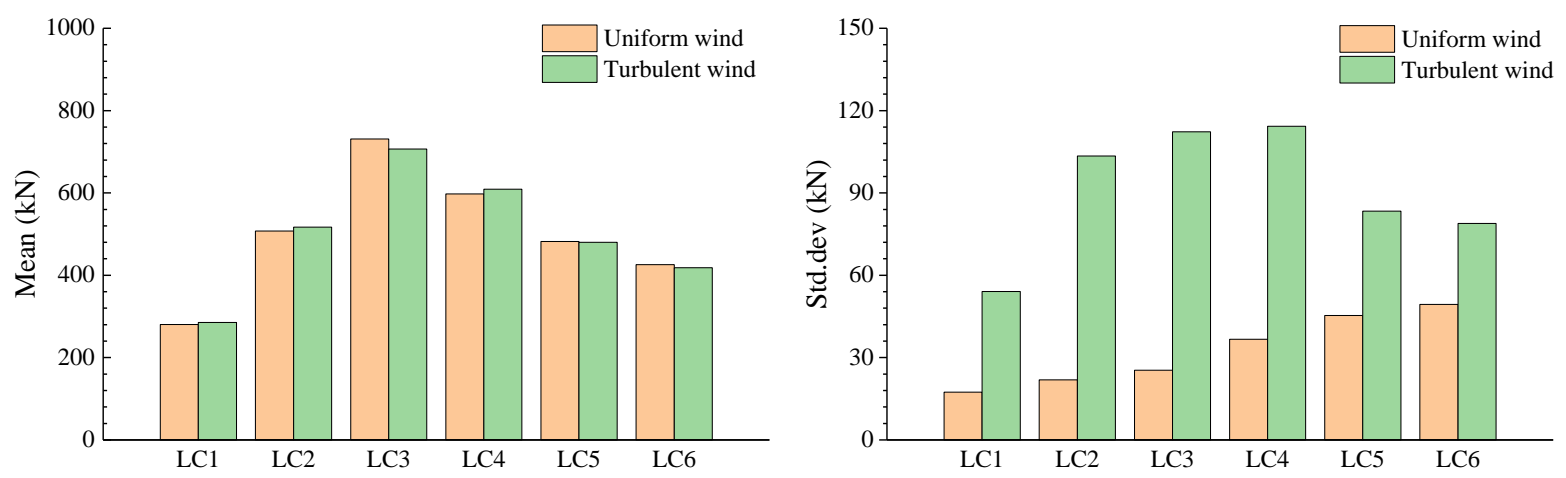

Fig. 14. Thrust force with various turbulence intensity. 


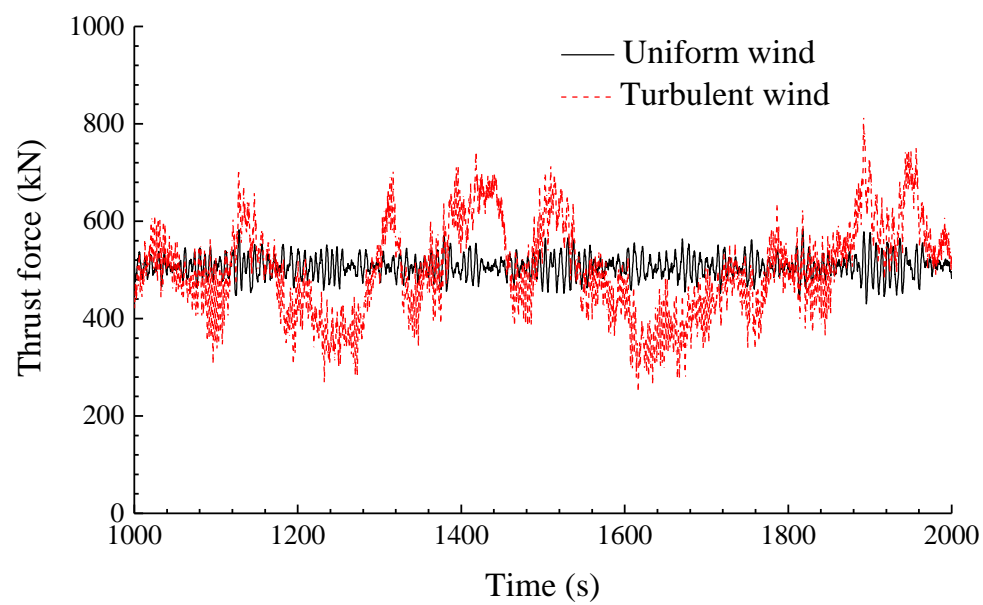

Fig. 15. Time-series of thrust force, LC2.

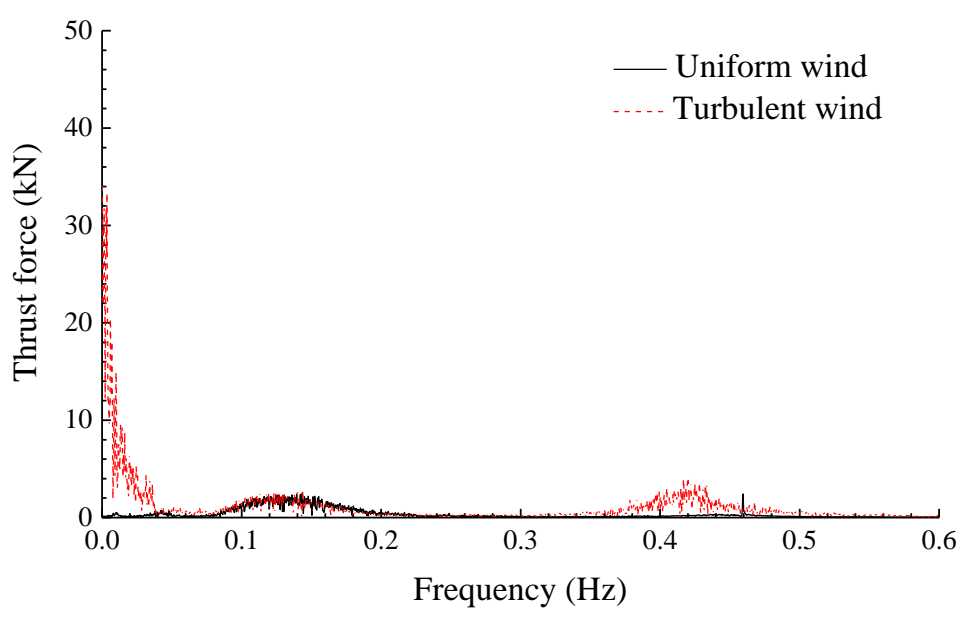

Fig. 16. FFT analysis result of thrust force, LC2.

The inflow turbulence influences not only the thrust force, but also the platform motions.

278 Considering that the surge natural period of the platform is sufficiently long (over 100 s [30]) and covered by the dominating frequency range of the wind spectrum, resonant surge motion may be excited.

280 Fig. 17 represents the FFT analysis result of platform surge motion, where two response peaks are 281 observed. The first peak is located around $0.9 \mathrm{~Hz}$, close to the wave energy frequency. This part of 282 motion is usually named as wave energy response, which is induced by first-order linear wave 283 excitations. Additionally, response is also observed around the natural period of surge motion, implying 284 that the resonant surge motion is excited by the second-order nonlinear wave drift forces. Due to the 285 slow-varying wind speed, the low frequency surge motion is amplified considerably by the inflow 286 turbulence. Nevertheless, the 3P rotor frequency response is not observed. It is mainly because the 3P 287 frequency is far from the resonant frequency of the platform so that the motions are not sensitive to the space scale turbulence. 


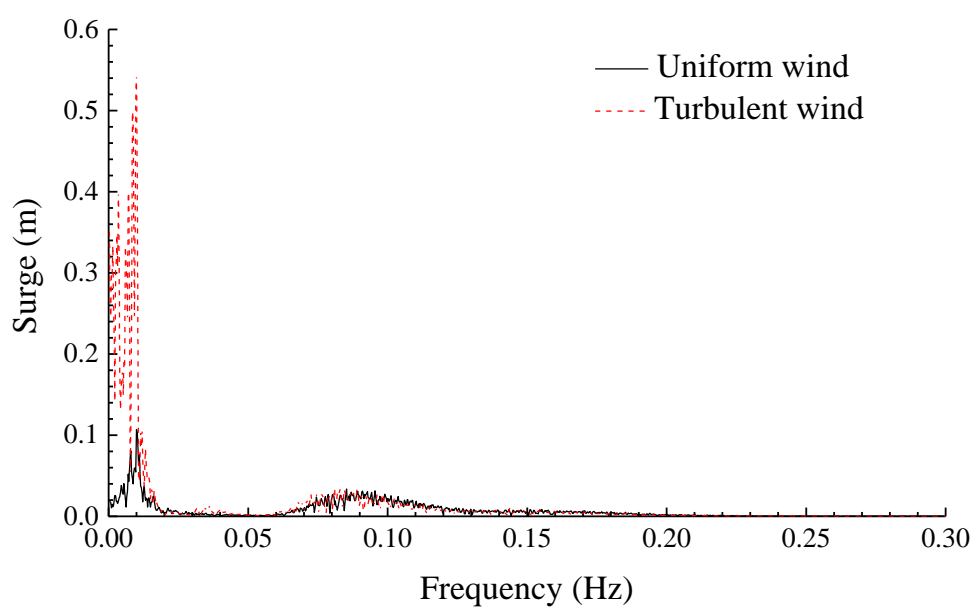

Fig. 17. FFT analysis result of platform surge motion, LC2.

\subsection{Power generation}

Fig. 18 represents the statistics of wind turbine power generation with respect to the three wind fields. In general, the average power generation is merely dependent on the mean wind speed whereas varies little with wind shear and inflow turbulence. The wind shear has a small influence on the fluctuation of power generation. Nevertheless, the standard deviation increases significantly once the floating wind turbine is subject to the turbulent inflow. According to Fig. 10, the standard deviation of wind speed variation increases with the mean wind speed, so that the fluctuation of the power generation should also be more noticeable. Such deduction is consistent with the variation trend in below-rated operational state (LC1-LC3). Nevertheless, the fluctuation of power is reduced in over-rated operational sate (LC4LC6), even if the wind field becomes more turbulent. It is attributed to the two controllers, which are active in different operational states. In the below-rated state, the variable-speed torque controller is active to maximise the power generation so that the power generation is very sensitive to the wind speed (see Fig. 5). In this case, the power generation reacts promptly to the variation of wind speed and thereby the standard deviation is augmented. Comparatively, it is the blade pitch controller that regulates the wind turbine in the over-rated operational state, which aims to keep the power generation at the rated value $5 \mathrm{MW}$. Consequently, the wind power remains relatively robust to the variation of wind speed. Since the blade pitch controller is not perfect and takes time to react to the inflow, the fluctuation of power generation is not omitted completely. 

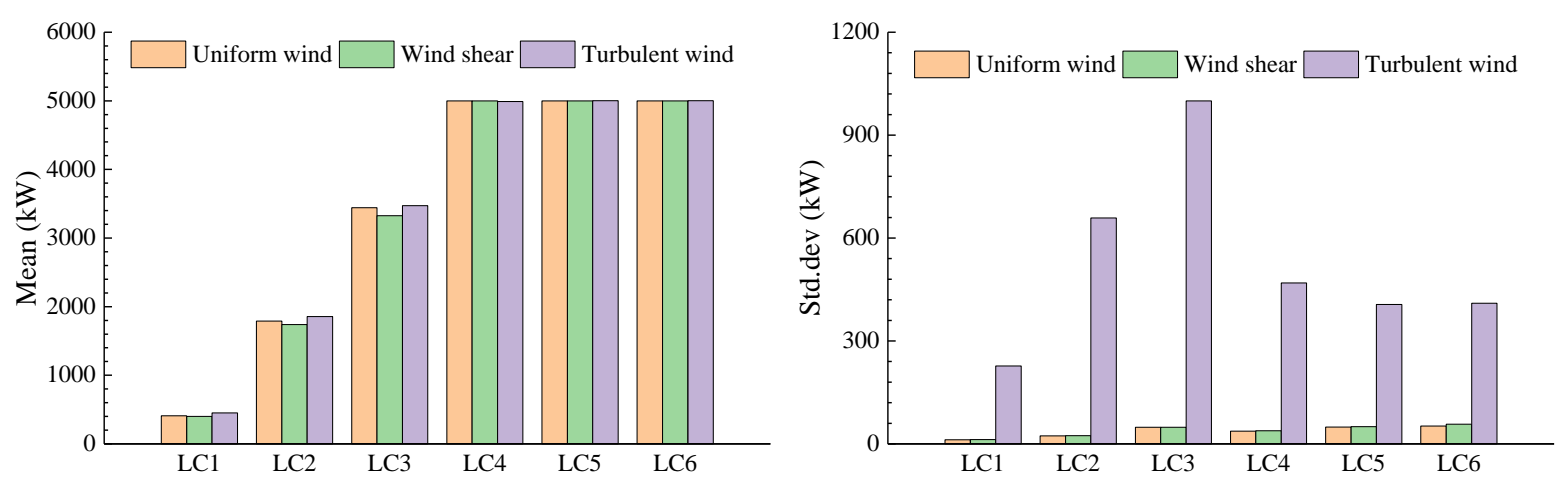

Fig. 18. Statistics of wind turbine power generation.

To figure out the dynamic feature of power generation, Fig. 19 demonstrates the FFT analysis result of power generation when the wind turbine is operating in below-rated state, where three regions are identified. This first region is located on the high frequency range where little response is observed. It is mainly because the turbulent wind is slow-varying, and the turbulence spectrum carries little energy around high frequency range (see Fig. 11). The power generation is most sensitive to the inflow turbulence in the intermediate range of frequencies. Within this region, the power generation increases rapidly as the varying frequency of the turbulent inflow reduces. The last region is the very low frequency range. In the very low frequency range, the power generation is not sensitive to the variation frequency of the turbulence. Similar phenomenon was observed in the field measurement of a full-scale 2.5 MW land-based wind turbine [16].

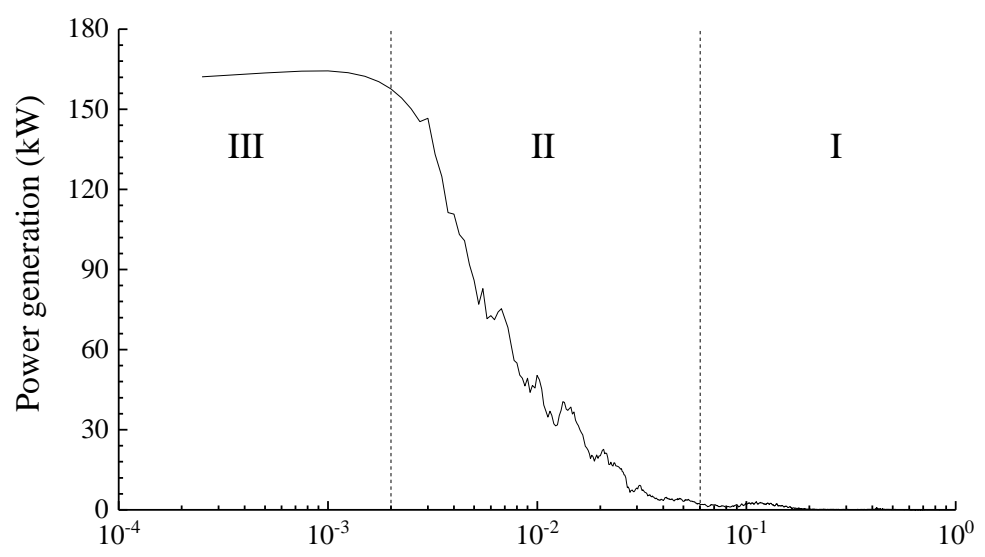

Frequency $(\mathrm{Hz})$

Fig. 19. FFT analysis result of power generation in turbulent wind, LC2.

Fig. 20 shows the spectral property of the power generation in over-rated operation state. Despite that three regions are identified, Fig. 20 shows a noticeable discrepancy compared with Fig. 19: the power generation reacts little to the very low frequency turbulence component. It indicates that the slow-varying turbulence is unable to stimulate strong fluctuation of power generation in the over-rated operational state. 


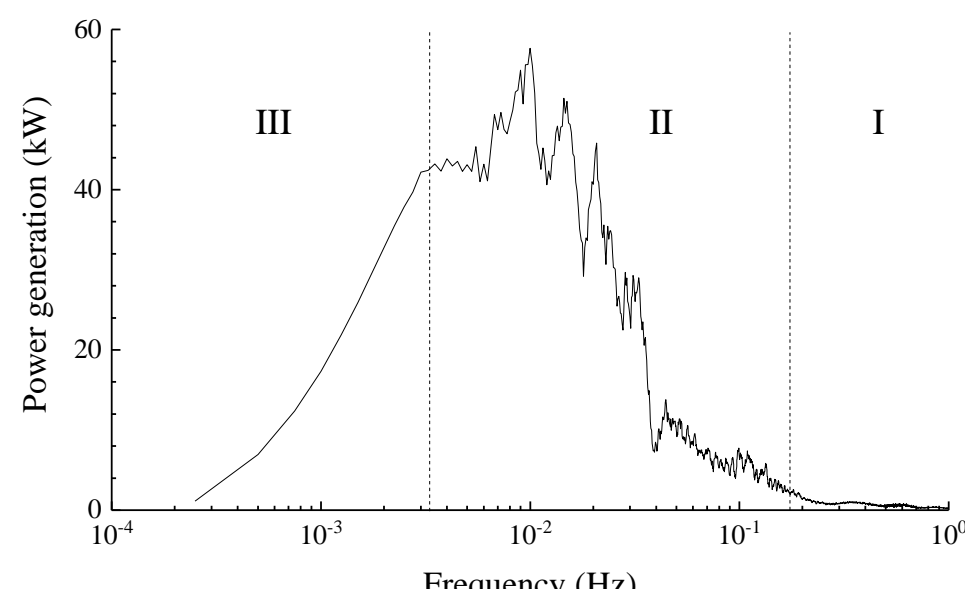

Fig. 20. FFT analysis result of power generation in turbulent wind, LC5.

According to Fig. 19 and Fig. 20, one can see that the power generation reacts to the very low frequency turbulence in different ways depending on the operational state. To interpret the mechanism behind, we run an extra simulation to examine the reaction of power generation to inflow with various oscillation frequencies, where the wind turbine is bottom-fixed and the wind shear is omitted. The timevarying inflow speed is defined as

$$
\begin{aligned}
& u(t)=u_{0}+\Delta u \sin (2 \pi f t) \\
& d u(t)=2 \pi f \cdot \Delta u \cos (2 \pi f t)
\end{aligned}
$$

where $u_{0}$ is the mean wind speed and $\Delta u$ is the speed fluctuation. Two frequencies $f$ are selected from the second and the third regions, namely $f=0.01 \mathrm{~Hz}$ and $f=0.001 \mathrm{~Hz}$. Also, $u_{0}=8.14 \mathrm{~m} / \mathrm{s}$ and $u_{0}=$ $18.31 \mathrm{~m} / \mathrm{s}$ are selected to represent below-rated and over-rated operational states, respectively. $\Delta u$ is set to $2 \mathrm{~m} / \mathrm{s}$ in all cases.

Fig. 21 illustrates how the wind turbine responds to the inflow turbulence at below-rated and overrated states, respectively. In the over-rated state, the power generation is nearly constant in the presence of very slow-varying inflow whereas the power fluctuation is noticeable when the frequency is sufficiently high. According to Eq. (10), the speed increment $d u$ of very low frequency turbulence component is very small. The blade pitch controller is able to compensate the tiny external disturbance and regulates the power generation. Consequently, the power generation reacts little to the very low frequency turbulence component and keeps at the rated value 5MW. When $f$ increases, the speed increment is augmented accordingly. The pitch controller can't afford to compensate the amplified disturbance, and unstable power generation occurs. It explains why the power production is robust to the very low frequency turbulence whereas sensitive to the moderate low frequency turbulence in Fig. 20. In the below-rated, nevertheless, the control objective is to maximize the power so that any tiny variation of inflow speed will change the power generation, regardless of the wind speed varying frequency (see Fig. 21(b)). In summary, the effect of inflow turbulence on the power generation is dependent on the operational state due to the control scheme of the wind turbine. 

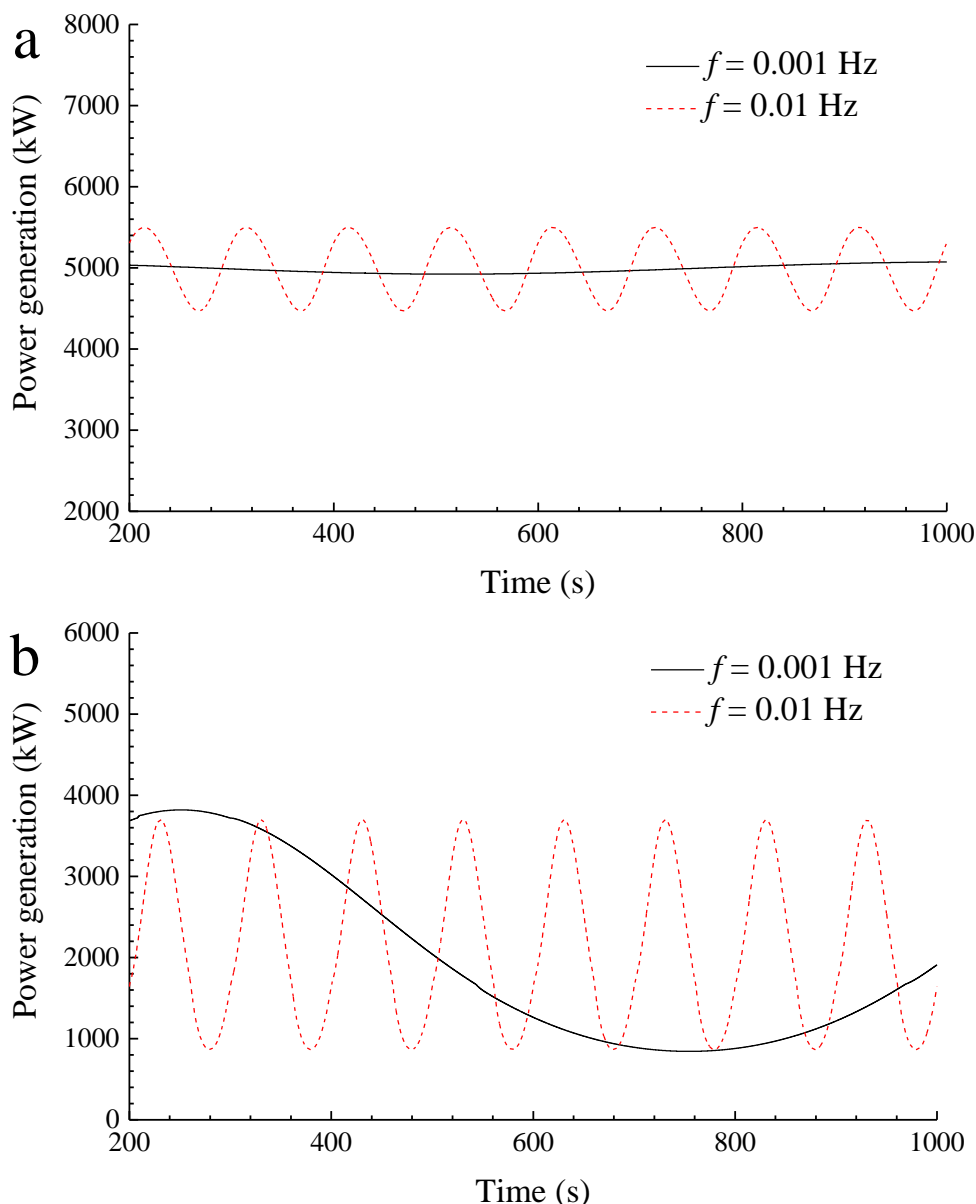

Fig. 21. Reaction of power generation of sinusoidal inflow. (a) over-rated state, $u_{0}=18.31 \mathrm{~m} / \mathrm{s}$. (b) below-rated state, $u_{0}=$ $8.14 \mathrm{~m} / \mathrm{s}$.

\subsection{Blade root bending moment}

The generator of a wind turbine is driven by the blade, and blade root is the connection point of blade and generator shaft. Therefore, blade root is a critical structure point, in terms of ultimate load and fatigue damage.

The ultimate blade root bending moment is estimated based on the mean up-crossing rate method.

The distribution of extreme value $M_{\max }$ is assumed to follow

$$
P\left(M_{\text {max }} \leq M_{0}\right)=\exp \left(-\int_{0}^{T} v^{+}\left(M_{0}, t\right) d t\right)
$$

where $v^{+}\left(M_{0}, t\right)$ is the up-crossing rate corresponding to level $M_{0}$, which denotes the instantaneous frequency of the positive slop crossings of the defined level. The mean up-crossing rate is given by

$$
\bar{v}^{+}\left(M_{0}\right)=\frac{1}{T} \int_{0}^{T} v^{+}\left(M_{0}, t\right) d t
$$

S-N method is used to evaluate the corresponding fatigue damage load. It is assumed that the damage accumulates linearly with each of hysteresis cycles according to Miner's Rule. In this case, the overall damage load $(D L)$ produced by all the cycles is given by 


$$
D L=\left[\frac{\sum\left(n_{i}\left(L_{i}\right)^{m}\right)}{n^{\text {STeq }}}\right]^{\frac{1}{m}}
$$

371 where $n^{S T e q}=f_{e q} \cdot T$ is the total equivalent fatigue counts, $f_{e q}(1 \mathrm{~Hz}$ in this paper) is the fatigue load frequency and $T$ is the simulation time. $n_{i}$ is the cycle count and $L_{i}$ is the cycle's load range about a fixed load-mean. $m$ is the Wholer exponent. Considering the geometry of the tower and the blade, the B1 category of S-N curve suggested by [31] is selected and $m$ is set to 4. It worth noting that other alternative approaches are available to estimate the fatigue loads. For example, Lind et al. [32] proposed a procedure to estimate the fatigue loads on wind turbines, based on stochastic differential equations.

Fig. 22 displays the estimated mean up-crossing rate of the blade root bending moment. Regardless of the operational state, the mean up-crossing rate is significantly increased by the inflow turbulence. For example, the ultimate bending moment hardly exceeds $7000 \mathrm{kN} \cdot \mathrm{m}$ in the uniform wind field. On the contrary, the mean up-crossing rate is as high as $10 \mathrm{~Hz}$ when the wind turbine is subject to turbulent wind. Obviously, the bending moment is unstable in the turbulent wind field so that it has a higher probability to exceed a certain level.
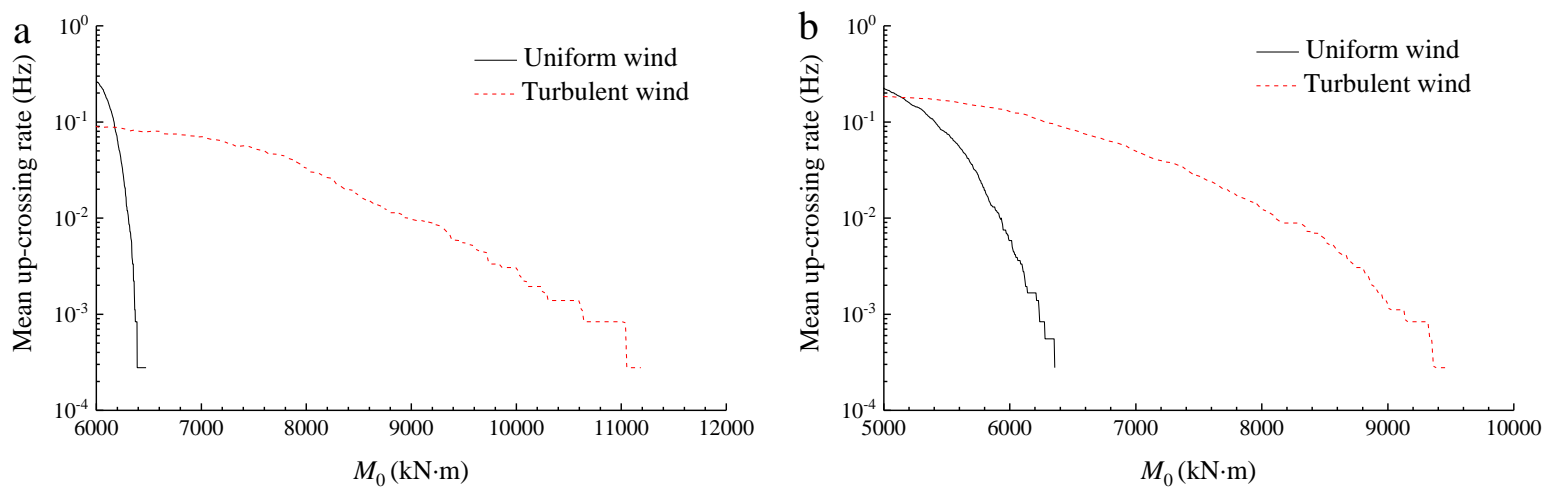

Fig. 22. Mean up-crossing rate of blade root bending moment, (a) LC2; (b) LC5.

Fig. 23 shows the fatigue damage load applied at the blade root. It is evident that the fatigue damage bending moment increases with the inflow turbulence. In general, the fatigue damage bending moment is doubled in the turbulent wind field. This is because the relative wind velocity seen by the blade becomes very unstable in the presence of turbulence, and the fluctuation of blade root bending moment is thus amplified. The result is that the load range of hysteresis cycle $L_{i}$ increases, augmenting the fatigue damage load. 


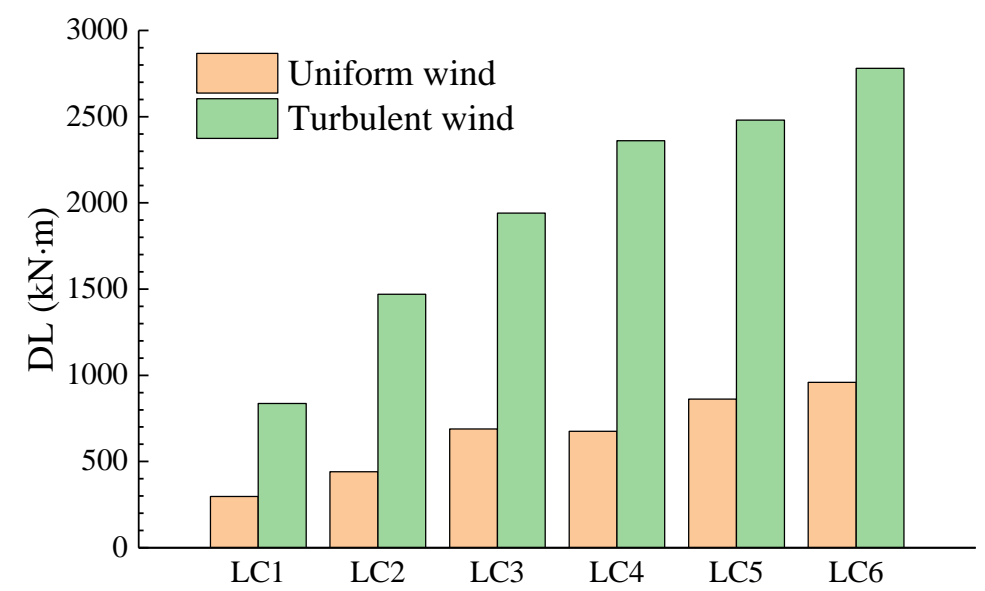

Fig. 23. Fatigue damage bending moment at blade root.

Although the wind shear has little influence on the thrust force and the power generation, the blade root bending moment is sensitive to wind shear. As shown in Fig. 24, the blade root bending moment of an individual blade experiences increased fluctuation in the presence of wind shear. According to the time-series, the dominating oscillating frequency of the bending moment is approximately $0.2 \mathrm{~Hz}$, close to the rotor speed. Apparently, this frequency is induced by both wind shear and tower shadow effect. Given that the fluctuation of bending moment is amplified, the mean up-crossing rate and fatigue load can be expected to increase accordingly. Fig. 25 and Fig. 26 supports this assumption. Due to the increased fluctuation, the ultimate blade root bending moment has a higher probability to exceeds a given level and the fatigue damage load accumulates more rapidly.

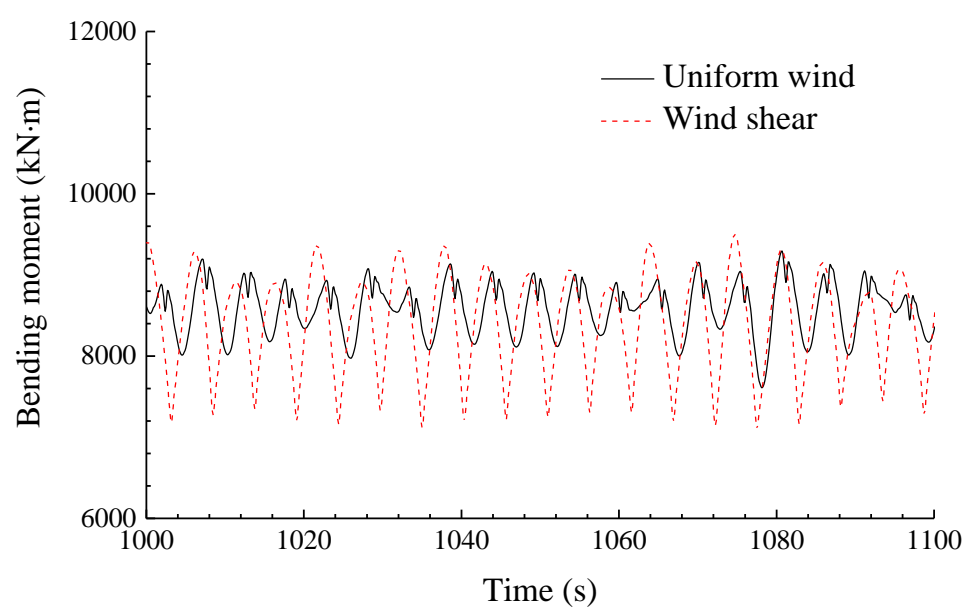

Fig. 24. Time series of blade root bending moment, LC3. 

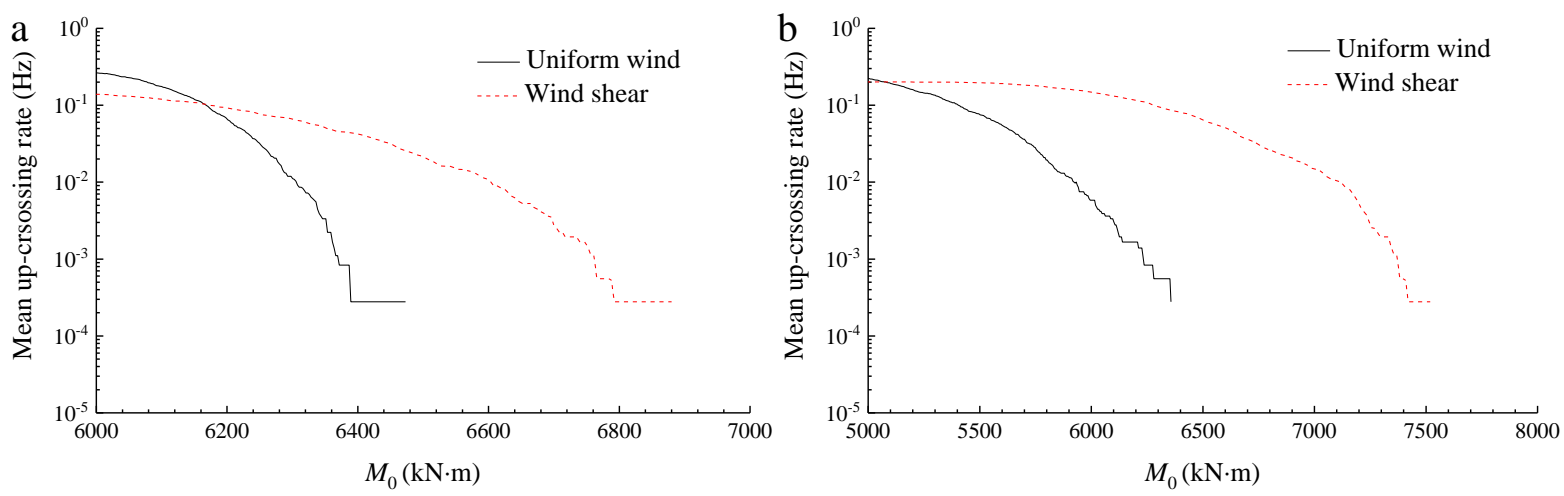

Fig. 25. Mean up-crossing rate of blade root bending moment, (a) LC2; (b) LC5.

406

407

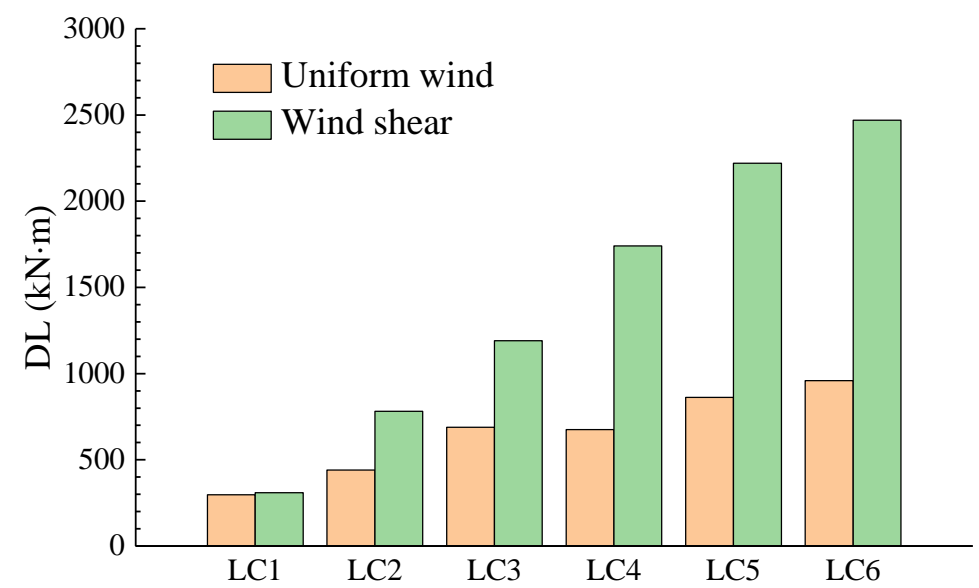

Fig. 26. Fatigue damage bending moment at blade root

Although the overall performance of the wind turbine is just sensitive to inflow turbulence, the local aerodynamic load at a single blade is nevertheless dependent on the wind shear. As well known, the blade is one of the critical components of a wind turbine, which dominate the life time. Therefore, the property of the local wind field must be carefully investigated.

\section{Conclusions}

The effects of wind shear and inflow turbulence on the performance of a semisubmersible offshore floating wind turbine are investigated in this work. A uniform wind field, a steady wind field with wind shear and a turbulent wind field are generated. Aero-hydro-servo-elastic coupled analysis is performed in time-domain to simulate the thrust force, the power generation and the blade root bending moment.

The wind shear has a limited influence on the rotor performance. Power generation and thrust force are just slightly varied in the presence of wind shear. Nevertheless, the wind shear has a noticeable effect on the local load applied at an individual blade.

Wind turbulence has a noticeable influence on the thrust force and the power generation. The fluctuations of the two items are augmented when the wind turbine is subject to turbulent wind. Analysis show that the reaction of power generation to very low frequency turbulence is dependent on the operational state, due to the control strategy of the wind turbine. The power generation is insensitive to 
very low frequency in the over-rated state whereas sensitive to any frequency turbulence in the belowrated state.

The ultimate and fatigue bending moment at the blade root is also examined. Both the ultimate and fatigue damage loads increase as a result of inflow turbulence and wind shear.

This study reveals that a uniform wind field is far from sufficient for the estimation of floating wind turbine behaviour. The wind shear and inflow turbulence must be taken into account to avoid premature failure.

\section{Acknowledgement}

The authors would like to acknowledge China Scholarship Council for the financial support (No. 201506230127).

\section{References}

[1] ExxonMobile. Outlook for Energy: A View to 2040. 2018; 10.

[2] Nielsen FG, Hanson TD, Skaare B. Integrated dynamic analysis of floating offshore wind turbines. Proceedings of the 25th Internatioanl Conference on Offshore Mechanics and Artic Engineering, Humburg. 2006; 1:671-679. http://doi.org/10.1115/OMAE2006-92291.
[3] Principle Power. WindFloat,

http://www.principlepowerinc.com/en/windfloat/; 2015

[accessed 27 March 2018]
[4] Statoil. World's first floating wind farm has started production,

https://www.statoil.com/en/news/worlds-first-floating-wind-farm-started-production.html/; 2017.

$$
\text { [accessed } 27 \text { March 2018] }
$$

[5] Li L, Gao Y, Hu ZQ, Yuan ZM, Day S, Li HR. Model test research of a semisubmersible floating wind turbine with an improved deficient thrust force correction approach. Renew Energ. 2018;119:95105. http://doi.org/10.1016/j.renene.2017.12.019.

[6] Duan F, Hu Z, Wang J. Model Tests of a Spar-Type Floating Wind Turbine Under Wind/Wave Loads. Proceedings of the 34th Internatioanl Conference on Offshore Mechanics and Artic Engineering, St. John's. 2015; 9: V009T09A044 . http://doi.org/10.1115/OMAE2015-41391.

[7] Goupee AJ, Koo BJ, Kimball RW, Lambrakos KF, Dagher HJ. Experimental Comparison of Three Floating Wind Turbine Concepts. J Offshore Mech Arct Eng. 2014;136(2):020906. http://doi.org/10.1115/1.4025804.

[8] Liu YC, Xiao Q, Incecik A, Peyrard C, Wan DC. Establishing a fully coupled CFD analysis tool for floating offshore wind turbines. Renew Energ. 2017;112:280-301. https:// doi.org/10.1016/j.renene.2017.04.052. 
[9] Li L, Gao Y, Yuan ZM, Day S, Hu ZQ. Dynamic response and power production of a floating integrated wind, wave and tidal energy system. Renew Energ. 2018;116:412-22. https://doi.org/ 10.1016/j.renene.2017.09.080.

[10] Li L, Cheng Z, Yuan Z, Gao Y. Short-term extreme response and fatigue damage of an integrated offshore renewable energy system. Renew Energ. 2018;126:617-29. https:// doi.org/10.1016/j.renene.2018.03.087

[11] Li L, Hu ZQ, Wang J, Ma Y. Development and Validation of an Aero-hydro Simulation Code for Offshore Floating Wind Turbine. J Ocean Wind Energy. 2015;2(1):1-11. [12] Liu YC, Xiao Q, Incecik A, Wan DC. Investigation of the effects of platform motion on the aerodynamics of a floating offshore wind turbine. J Hydrodyn. 2016;28(1):95-101. https://doi.org/10.1016/S1001-6058(16)60611-X

[13] Orlanski I. A rational subdivision of scales for atmospheric processes. Bulletin of the American Meteorological Society. 1975:527-30. [14] Lubitz WD. Impact of ambient turbulence on performance of a small wind turbine. Renew Energ. 2014;61:69-73. https://doi.org/10.1016/j.renene.2012.08.015.

[15] Li QA, Murata J, Endo M, Maeda T, Kamada Y. Experimental and numerical investigation of the effect of turbulent inflow on a Horizontal Axis Wind Turbine (Part I: Power performance). Energy. 2016;113:713-22. https://doi.org/10.1016/j.energy.2016.06.138 [16] Chamorro LP, Lee SJ, Olsen D, Milliren C, Marr J, Arndt REA, et al. Turbulence effects on a fullscale $2.5 \mathrm{MW}$ horizontal-axis wind turbine under neutrally stratified conditions. Wind Energy. 2015;18(2):339-49. https://doi.org/10.1002/we.1700 [17] Lee KY, Tsao SH, Tzeng CW, Lin HJ. Influence of the vertical wind and wind direction on the power output of a small vertical-axis wind turbine installed on the rooftop of a building. Appl Energ. 2018;209:383-91. https://doi.org/10.1016/j.apenergy.2017.08.185.

[18] Shen X, Zhu XC, Du ZH. Wind turbine aerodynamics and loads control in wind shear flow. Energy. 2011;36(3):1424-34. https://doi.org/10.1016/j.energy.2011.01.028 [19] Sezer-Uzol N, Uzol O. Effect of steady and transient wind shear on the wake structure and performance of a horizontal axis wind turbine rotor. Wind Energy. 2013;16(1):1-17. https://doi.org/10.1002/we.514 [20] Dolan DSL, Lehn PW. Simulation model of wind turbine 3p torque oscillations due to wind shear and tower shadow. IEEE Tranc Energy Conver. 2006;21(3):717-24. http://doi.org/10.1109/TEC.2006.874211.

489 [21] Li Y, Castro AM, Sinokrot T, Prescott W, Carrica PM. Coupled multi-body dynamics and CFD 490 for wind turbine simulation including explicit wind turbulence. Renew Energ. 2015;76:338-61. https://doi.org/10.1016/j.renene.2014.11.014. 
492 [22] Robertson A, Jonkman J, Masciola M, Song H, Goupee A, Coulling A, et al. Definition of the 493 semisubmersible floating system for phase II of OC4. National Renewable Energy Laboratory (NREL), 494 Golden, CO.; 2014.

495 [23] Jonkman JM, Butterfield S, Musial W, Scott G. Definition of a 5-MW reference wind turbine for 496 offshore system development. National Renewable Energy Laboratory Golden, CO; 2009.

497 [24] Coulling AJ, Goupee AJ, Robertson AN, Jonkman JM, Dagher HJ. Validation of a FAST semi498 submersible floating wind turbine numerical model with DeepCwind test data. Journal of Renewable 499 and Sustainable Energy. 2013;5(2):023116. https://doi.org/10.1063/1.4796197.

500 [25] Jonkman JM, Buhl Jr ML. FAST User's Guide. National Renewable Energy Laboratory (NREL); 5012005.

502 [26] Minnema JE. Pitching moment predictions on wind turbine blades using the Beddoes-Leishman 503 model for unsteady aerodynamics and dynamic stall: Department of Mechanical Engineering, 504 University of Utah, 1998.

505 [27] Johannessen K, Meling TS, Hayer S. Joint distribution for wind and waves in the northern north 506 sea. Proceedings of 17th International Offshore and Polar Engineering Conference, Stavanger, 2001; $507 \quad 3: 19-28$.

508 [28] International Electrotechnical Commission. Standard: IEC 61400-1 Wind turbines part 1: Design 509 requirements. 2015.

510 [29] Lind PG, Vera-Tudela L, Wahter M, Kuhn M, Peinke J. Normal Behaviour Models for Wind 511 Turbine Vibrations: Comparison of Neural Networks and a Stochastic Approach. Energies. 512 2017;10(12):1944. https://doi.org/10.3390/en10121944.

513 [30] Li L, Hu Z, Wang J, Hu Q. Dynamic Responses of a Semi-type Offshore Floating Wind Turbine. 514 Proceedings of the 33rd Internatioanl Conference on Offshore Mechanics and Artic Engineering, San 515 Francisco. 2014; 9A: V09AT09A009. https://doi.org/10.1115/OMAE2014-23182.

516 [31] Det Norske Veritas. Fatigue design of offshore steel structures. Standard: DNV-RP-C203. 2010.

517 [32] Lind PG, Herraez I, Wachter M, Peinke J. Fatigue Load Estimation through a Simple Stochastic 518 Model. Energies. 2014;7(12):8279-93. https://doi.org/10.3390/en7128279. 